\title{
The radiation therapy in keloids treatment: a comprehensive review of pathomechanism, damage mechanisms and cellular response
}

\author{
Jing $\mathrm{Xu}^{1}$, Elan Yang${ }^{2}$, Nan-Ze Yu ${ }^{2}$, You-Bin Wang², Xiao Long ${ }^{2}$ \\ ${ }^{1}$ Peking Union Medical College, Beijing 100730, China. \\ ${ }^{2}$ Department of Plastic Surgery, Peking Union Medical College Hospital, Beijing 100730, China.
}

Correspondence to: Dr. Xiao Long, Department of Plastic Surgery, Peking Union Medical College Hospital, Shuaifuyuan 1\#, Beijing 100730, China. E-mail: pumclongxiao@126.com

How to cite this article: $\mathrm{Xu} \mathrm{J}$, Yang E, Yu NZ, Wang YB, Long X. The radiation therapy in keloids treatment: a comprehensive review of pathomechanism, damage mechanisms and cellular response. Plast Aesthet Res 2017;4:116-26.

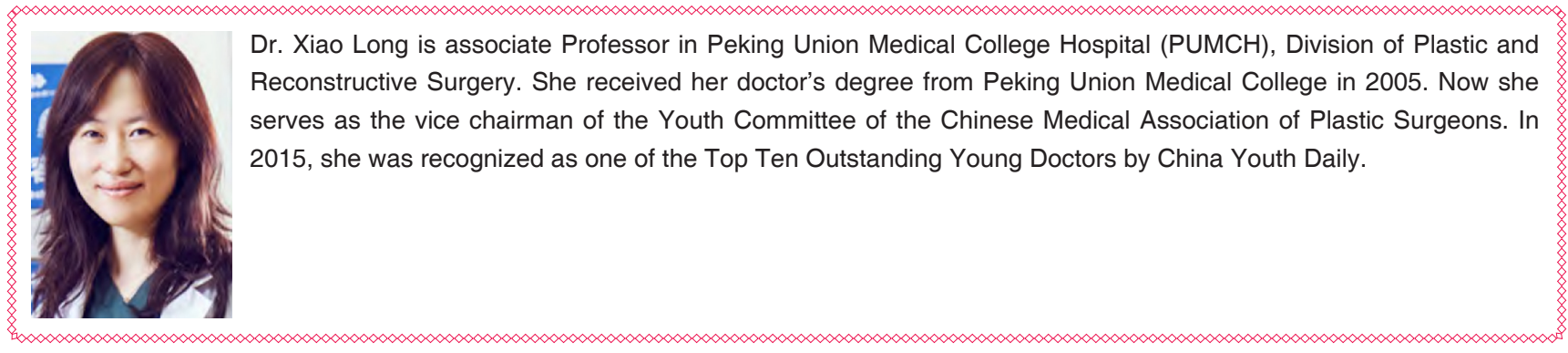

Article history:

Received: 21-03-2017

Accepted: 15-07-2017

Published: 28-07-2017

Key words:

Radiation therapy,

keloids,

combination therapy

\begin{abstract}
Keloid management has always been frustrating and challenging. The combination therapy of surgical excision and radiation therapy was deemed as the last resort for decades. The authors performed a thorough and comprehensive review over the mechanisms on how radiation therapy damages the keloid cells. The keloid cells' cellular response towards damage induced by irradiation was also studied based on original and current literatures. Mechanisms of damage generated by radiation therapy on keloid cells remained partially understood. However, direct damage was identified playing dominant role, in contrast to damage involved cancer cell apoptosis. Moreover, the p53 pathway and some inflammatory factors like interleukin-6 were believed to function in cellular response to irradiation. However, the transforming growth factor beta, which was the major dysregulated pathway involved in pathogenesis of keloid formation showed no apparent correlation with cellular response to irradiation damage. These pathways could partially explain radiation resistance in some refractory keloid lesions. The scientific basis and experimental proof in this field was still inadequate, which drove us to find more evidence to identify the key regulator response to damage engendered by radiation therapy. Further pathway identification may benefit the drug development to prevent keloid recurrence.
\end{abstract}

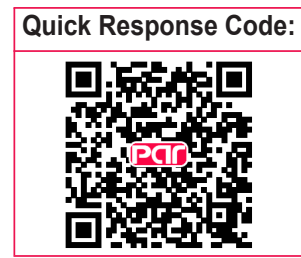




\section{INTRODUCTION}

Keloids have been considered frustrating issues for many decades since surgeries evolved. The keloids were firstly considered as pathological wound healing process. Deemed as benign tumors, keloids were uncontrolled and unconfined sharply bounded hyperplasia of dermal connective tissues arising from an abnormal wound healing process. This benign lesion often follows dermal injury, burn injury, tattooing and even simple acnes. However, the cause of keloid formation remained a mystery. Familial tendency and darker skin races preference were observed in prevalence of this benign disease. ${ }^{[1]}$ The keloid is gradually considered as a genetic disease with genetic predisposition that demonstrates an autosomal dominant or X-linked inheritance pattern. Even though there was no specific genes identified directly related to keloid formation, several susceptibility loci were reported before. In one study utilizing genomewide sequencing technology to discover susceptible loci, 4 potential single-nucleotide polymorphisms in 3 chromosomal regions in Japanese patients were

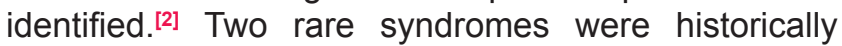
named due to its familial tendency, the RubinsteinTaybi syndrome and Goeminne syndrome.

Black people are more likely to have this benign lesion, while the Caucasians are least likely. In African populations, the incidence is $6-16 \%$, which is 15 times higher than whites..$^{[3]}$ The more piercing happened among women might bring the confounding bias which leads to female predominance. ${ }^{[4]}$

Moreover, keloid growths are more likely seen on the chest, shoulders, upper back, back of the neck and earlobes, where larger skin tension should be noted. Notably, the earlobe is exceptional, which indicate lower recurrence rate under similar treatment. Therefore, this site-specific characteristic provides us the site-specific treatment algorithms, for example, to decide whether or not the lesion requires radiation therapy. There were several characteristics of keloids, several morphological and histological differences. It is also noted that, the hypertrophic scarring and keloids often confuse dermatologists and surgeons when it comes to diagnosis due to their similar appearances.

Clinically, keloids are firm nodules, which can be skin colored, dispigmented, or erythematous secondary to telangiectasias. The keloid scars in Caucasian people, are more likely to be erythematous and telangiectatic. Comparatively, hyperpigmentation is more popular in Blacks. ${ }^{[5]}$ The lesion always extends beyond the border of dermacated primary lesion, and often with irregular shape, just like how the word "keloid" originated from the Latin word "crab". However, the hypertrophic scars are apparently more linear, nodular, or papular with more regular borders and are always within the original wound borders.

The hypertrophic scars usually occur 4 to 8 weeks postoperatively or after the injury, compared to high variability of keloids formation time. The time of keloid formation can be quite volatile, from generally within 3 months to many years after the dermal injury. Unlike the hypertrophic scars, which often gradually regress after years, keloids persist for longer period of time and do not regress spontaneously. Moreover, even both lesions are pruritic, the keloids are more likely to cause significant pain and hyperesthesia.

\section{PATHOPHYSIOLOGICAL BASIS OF KELOIDS FORMATION}

Keloids can derive from any form of dermal injury. However, the pathological process of its formation is still poorly understood. Both environmental and genetic factors contribute to this pathological process. Apparently, a universally accepted theory is that both keloids and hypertrophic scars are considered results of persistent chronic inflammation. In histological view, continuous local inflammation was observed along with keloid progression. ${ }^{[6]}$ Inflammatory cells, increased numbers of fibroblasts, angiogenesis, and new collagen deposition were all observed. Besides, inflammatory cytokines or mediators were also overproduced in keloids or hypertrophic scar tissues, including interleukin (IL)-1 $\alpha, \mathrm{IL}-1 \beta$, IL-6, and tumor necrosis factor (TNF)- $\alpha$. These pro-inflammatory genes or products are believed to be sensitive to trauma, induce continuous inflammation and collagen deposition. Moreover, persistent chronic inflammation could potentially explain the relative higher invasiveness of keloid scars. The major occasion where inflammation happened, reticular dermis is believed to function primarily in keloid formation. This theory is partly supported by the valid therapeutic value of corticosteroids injection/tape/ointment in keloid treatment. Besides, one of the many widely accepted theories is that more injury and inflammation will more likely generate excessive scar tissue. A multitude of cells were involved in wound healing process, as well as keloid scarring. One of the very important cells, fibroblast produce collagen show sustained activity. ${ }^{[7]}$ Aberrantly excessive growth factor and overproduction of its receptors were both observed in growth pattern of keloid-derived fibroblasts. Overexpression of vascular endothelial growth factor (VEGF), transforming growth factor (TGF)- $\beta 1$, TGF- $\beta 2$, connective tissue growth factor, insulin-like growth factor (IGF)-1, as well as the 
platelet-derived growth factor (PDGF)- $\alpha$ receptor were all reported in previous studies ${ }^{[8]}$ Alterations of these growth factors secretion were believed to be pivotal for scarring process. Keloid-derived fibroblasts were reported more sensitive to several key growth factors like TGF- $\beta 1$, PDGF and IGF-1 compared to normal fibroblasts, which might explain the overproduction of collagen by keloid-derived fibroblasts. ${ }^{[9]}$ Moreover, other than the collagen-producing cells fibroblasts, keratinocytes isolated from keloid formation also were shown to have an aberrant behavior, especially co-cultured with fibroblasts. Two vital cytokines were believed secreted from keloid-derived keratinocytes, the hypoxia-inducible factor-1 $\alpha(\mathrm{HIF}-1 \alpha)$ and release of IL-1. ${ }^{[10]}$ Some paracrine secretion by keloids were also deemed as contributor to fibroblasts overgrowth and collagen overproduction. ${ }^{[11]}$ What's more, melanocytes, mast cells and myofibroblasts were also all considered playing important roles in keloid scarring. ${ }^{[12,13]}$

As pathomechanism parallel to skin fibrosis, TGF- $\beta$ was currently considered as one of the key regulators in keloid formation. TGF- $\beta$ is the cytokine with a wide variety of biological function implicated in other fibrotic disorders. Stimulation of cell proliferation and cellular differentiation made TGF- $\beta$ family a very important mediator in wound repair process, especially functioning in extracellular matrix production. In normal wound healing process or hypertrophic scarring, TGF$\beta$ 's activity will finally regress accompanied with wound sites to be mature. However, in pathological process, like keloid formation, TGF- $\beta$ 's expression level and activity remain sustainably upregulated. ${ }^{[14]}$ SMAD signal-transduction pathway, as the major downstream mediator of TGF- $\beta$, is believed to be dominant in keloid scarring process. Upregulated TGF- $\beta$ diminishes the SMAD3 expression, which subsequently increase procollagen gene expression and enhance ECM deposition. ${ }^{[15]}$ Except for TGF-SMAD pathway, other pathways involved in other fibrotic disorder or solid tumors were also reported playing roles in keloid formation at different levels, like p53 and mTOR. ${ }^{[16]}$ These pathways also provide us with substantial background when studying keloid's response to radiation.

\section{MANAGEMENT OF KELOIDS}

Management of keloids was considered a conundrum without definitive optimal treatment strategies. A wellestablished treatment strategy was reported before, mentioning a new emerging treatment strategy comprised of surgical excision, radiation, corticosteroid injection, laser and conservative multimodal therapy. The current mainstream of current definitive treatment strategies emphasized on 5 major treatment modality, including intralesional corticosteroid injection, cryotherapy, surgical manipulation, radiotherapy and laser therapy. Intralesional injections started since 1960s, but demonstrating various but limited clinical outcome. The suppression effect of topical inflammation is considered the basis of intralesional corticosteroid injection. ${ }^{[17]}$ Diminished collagen or extracellular matrix and inhibition of fibroblasts migration were both reported. However, the response rate was quite uncertain, varying from $50 \%$ to $100 \% .{ }^{[18,19]}$ The control of recurrence rate was also fluctuating, ranging from less than $10 \%$ to over $50 \%$. ${ }^{[20,21]}$ The most common adverse effects included dermal atrophy, telangiectasia and local pain at the injection site. Another monotherapy utilized accompanied with less trauma is cryotherapy, which is believed to function through vascular damage, then anoxia and tissue necrosis. ${ }^{[22]}$ The success rate ranges from $32 \%$ to $74 \%$ when utilized for at least two sessions. The adverse effects were quite similar to intralesional corticosteroid injection. Botulinum toxin A injected intralesionally was considered as another critical way to treat keloids, effective but better tolerated than intralesional steroid. ${ }^{[23]}$ Besides, both intralesional corticosteroid injection and botulinum toxin $\mathrm{A}$ injection are combined with other therapies, especially radiation therapy. Furthermore, laser treatment is another modality proved to be effective in controlling keloid formation. Since the 1980s, multiple laser treatment modalities were introduced for keloids and hypertrophic scars, such as carbon dioxide laser and 585-nm pulsed-dyelaser (PDL) laser. Notably, PDL laser is nowadays considered the most effective among all laser treatment utilized, especially initial hypertrophic scars or primary keloids. ${ }^{[24]}$ Laser treatment can control keloid growth through generating ischemic microenvironment. Besides, more and more treatment modalities were utilized, generating different clinical outcome. The major adjuvant preventative therapy includes pressure, silicone gel sheeting, flavonoids. Some other drugs, especially chemotherapeutic or immune suppressive drugs, such as 5-fluorouracil (5$\mathrm{FU})$, Bleomycin, mitomycin $\mathrm{C}$, botulinum toxin were also applied to treat keloids.

\section{Surgery and radiation therapy}

Lastly, as one of the traditional treatment for keloids and hypertrophic scars, surgical treated lesions alone have a recurrence rate ranging from $45 \%$ to $100 \%$. The surgery is believed to be another skin trauma which potentially causes more damage than before. Then the combination therapy of surgery and other post-operative treatment became popular around the world. Among these treatment modalities, combination therapy of surgical excision and radiation therapy was 
considered as the last resort which can significantly reduce recurrence rate. ${ }^{[25]}$ Notably, the definition of recurrence is controversial which might cause bias in clinical studies. The universally accepted definition was an elevation of the scar, extending beyond the original surgical field. ${ }^{[26]}$ Early in 1970s, several negative results drew the determined conclusion that simply surgical excision was accompanied with high rate of recurrence, ranging from $40 \%$ to $100 \% .{ }^{[27]}$ The possible explanation was surgery itself was considered as the stimulation of additional collagen synthesis. Therefore, the surgical excision was no longer used alone. The combination therapy of surgical excision and radiation therapy gradually replace the traditional surgical excision. Starting from superficial X-ray irradiation, the radiation therapy effectiveness was gradually proven. Radiation therapy has a long history being applied in treating keloids. The inhibition of scar growth and postoperative keloids formation was found back to early in the 20th century. DeBeurman and Gougerot first described X-ray treatment of keloids in 1906 and serial positive reports followed. ${ }^{[2]}$ First recommended in keloids prevention and then escalated to keloids treatment. ${ }^{[29]}$ Meanwhile, the rapid technology development also contributed to extension of radiation therapy application in treating keloids. From kilovoltage irradiation to electron beam irradiation, from outside of the body to inside of the body, the transition of technology brought improvement recurrence rate reduction and better normal tissue sparing. As one of the experienced radiation therapy center, our team is quite familiar with this combination therapy. Actually, different radiation therapy facility, technology, different treatment modality combined and different treatment protocol will cause variable clinical outcome. For example, due to the radiation therapy center of our hospital, we here gave our recommendation of our treatment modality. The first radiation therapy should be performed within $48 \mathrm{~h}$ postoperatively or after other procedures. The radiation therapy was performed 1st day postoperatively and on the 8th day of hypofractions as reported by Shen et al. ${ }^{[30]}$ previously. The external beam was administered using 6 or $7 \mathrm{MeV}$ electrons. Flat lesion surface was largely achieved by patient position change confirmed by radiation therapists. The field of irradiation field covered the entire lesion site with $1 \mathrm{~cm}$ margin to ensure the enclosure the margin. Normal tissue shielding was implemented by appliance of a $0.8 \mathrm{~cm}$ customized lead sheet. Additionally, $0.5 \mathrm{~cm}$ of wax was utilized to broaden the radiation field. For every single lesion, a total dose of $18 \mathrm{~Gy}$ in 2 fractions with interval of 1 week was well established. In a brief summary, the relative low $\bar{a} / \beta$ ratio of lower fractions and higher doses were presumed as the choice of treatment. Ranging from superficial X-rays, to electron- beam irradiation and to low dose rate or high dose rate brachytherapy, radiation therapy technology treatment has provided us with several options on different lesions and different sites. However, we still believe that the damage mechanism and the mechanism behind resistance generation are largely similar among all radiation therapy types. Moreover, the cellular response to radiation therapy was rendered as a possible explanation accounting for local recurrence. Indeed, what role did irradiation played remained unclear. We now present a comprehensive review over this issue, trying to identify the most valuable pathway involved in cellular response to irradiation.

\section{POTENTIAL MOLECULAR PATHWAYS AND CELLULAR RESPONSE}

Unfortunately, no present literatures could perform a thorough review on the ways which irradiation played. It might be attributed to the diversity of irradiation source and particles or uncertainty of molecular pathways dominance in keloid formation. A fraction dose of 5 Gy was considered effective in eliminating aberrantly activated fibroblasts and promoting the rest of normal fibroblasts. ${ }^{[31]}$ Similarities of direct damage and cellular response to ionizing irradiation could bring us some potential inspirations. Genetic susceptibility, radiosensitivity and complications were taken into our consideration. As known to us, the biological effectiveness of radiation was quite dependable owing to different sites, linear energy transfer (LET), total dose, fractionation rate and radio-sensitivity. Various mechanisms were reportedly involved in killing cancer cells or benign tumor cells. Early explanation was built on the hypothesis that local fibroblasts which were destroyed by irradiation cannot be replaced by distant fibroblasts. ${ }^{[32]}$ Under light microscope, programmed cell death or apoptosis dominated in post-irradiated targeted tissues. Apoptotic numbers and ratio in postoperative keloid tissues were considered as very important index evaluating the radio-sensitivity and direct DNA damage. Correspondingly, necrosis, mitotic cell death or mitotic catastrophe, senescence, autophagy were also observed and partially proved in some in vitro studies. ${ }^{[33]}$ The intracellular target was apparently the DNA, whose damage can cause irreversible cell injury or triggering the programmed cell death. The most effortless classification of these damages was naturally dividing them into two parts, direct damage and indirect damage. Direct damage essentially referred to the interaction between radiation and DNA, while indirect damage referr to the damage from radiation-derived free radicals. Direct actions dominate in high-LET ionizing irradiation technology (neutrons and other heavier ions), generating high- 
density energy deposition. ${ }^{[34]}$ On the contrary, lowLET ionizing irradiation technology (X-rays, gammarays and electrons) addresses the indirect actions, accomplishing a ratio between indirect and direct actions. Both of these actions achieve lethal DNA damage, comprising single strand DNA breaks, double strand DNA breaks and DNA cross-linking. Even though most of these damages can be repaired by efficient base repair excision system. A small fraction of complex DSB, however, was the exception, which leads to ultimate cell death. As for cancer cells, complexity of mechanisms induced a variety of cell death mentioned above, having many pathways assumed. One previous study made use of cancer patients' microarray data prior- or post-irradiative to obtain differentially expressed genes, protein domain enrichment analysis also help to highlight some related pathways ${ }^{[35]}$ Notably, deemed as the aberrant wound healing process, collagen synthesis related genes were also unearthed. The collagen triple helix repeat family members collagen type (COL) $5 \mathrm{~A} 2$, COL9A3, COL6A3, COL21A1, COL5A3, COL11A1, COL7A1 was significantly identified by protein-protein interaction. Notably, there was no clear evidence explaining the exact mechanisms other than direct damage towards DNA. We not only want to extract the molecular pathways from closely related research but also provide insights from keloid formation process and cancer cell response towards radiation therapy.

\section{P53 and apoptosis}

Even the pathways were not fully elucidated, direct and indirect DNA damage will be largely repaired by the cell DNA repair system, generating G1/G2/M block. However, the cellular response and characteristics of targeted tissue cells are quite complicated. Genomic instability and chromosome aberrations were observed in vitro studies by radiation induction apoptosis. Being the principle guardian of DNA damage response, p53 accordingly maintains the genetic stability through phosphorylated ATM or phosphorylated ATR proteins. ${ }^{[36]}$ ATM-p53-Bax-cytochrome C was reportedly associated with apoptosis, while the p53-Capspasescytochrome c pathway mitotic catastrophe-related. ${ }^{[37,38]}$ What's more, p53 also enabled extrinsic CD95-FADDcaspases apoptotic pathway, which is considered to be enhanced by CD-95 mediated pathway. ${ }^{[34]}$ Senescence was also believed to have p53 regulation involved. [39] Dysregulated p53 expression and function plays a critical role in tumorigenesis of diversified malignant tumors. Abnormal expression of p53 in non-neoplastic lesions and benign neoplasmas of soft tissue including keloids was also brought to light early in 1993, positivity in 9 of 9 keloids tissues baffling researchers whether it indicated malignancy. ${ }^{[40-42]}$ Further genetic studies ensued to elucidate the biological significance of the aberrant expression of p53 benign soft tissue lesions. As keloids gradually being considered as dysregulated wound healing process, a study randomly selected 20 archival-paraffin-embedded keloid samples for an immunoperoxidase assay with antibodies against fas, p53, bcl-2, and bcl-x using target antigen-retrieval technique. ${ }^{[43]}$ Among them, 18 of 20 keloids expressed p53 protein, while bcl-2 was expressed in 19 of 20 fibroblasts, which indicated that focal dysregulation of p53 combined with upregulation bcl-2 might help produce a combination of increased cell proliferation and decreased cell death in keloids. Prominent Fas expression was detected in all 20 specimens, limited to the central area, favoring the potential hypothesis that p53-induced Fas apoptotic process dysregulated in keloid hyper-proliferative area. Another study in exploration differences in different regions in entire keloid tissue, the "older parts of the keloid", the central parts of keloids are shrunken and soft in texture compared with peripheral keloids tissue parts, showing much less proliferative and invasive characteristics. ${ }^{[44]}$ With majority of fibroblasts derived from keloid centers staying in $\mathrm{G} 0$ or $\mathrm{G} 1$ phase, Fas and $\mathrm{Bcl}-2$ expression did not differ significantly between the two regions, but p53 expression was much higher in fibroblasts derived from central parts than from peripheral parts. ${ }^{[45]}$ Based on these molecular explanations for cells' overgrowth in keloid tissues, experimental 5-FU modality induced p53 and p21 accumulation together with a decrease in cyclin $\mathrm{B} 1$ and $\mathrm{Bcl}-2$ levels in treated keloid fibroblasts. ${ }^{[46,47]}$ Further evidence uncovered several possible explanations for how p53 played in keloid scarring. As a sequence-specific transcription repressor of $p 53$, overexpression of $\Delta \mathrm{N} 63$ isoform showed essential dominance in suppressing $\mathrm{p} 53$ protein in keloid tissues compared to normal skin, with the similar nuclear localization like p53 protein. ${ }^{[48,49]}$ Dysregulated p53 function, altered expression and asymmetric protein deposition observed in keloid tissues all enables its potential as the main target. Both contribution to intrinsic and extrinsic apoptotic pathway, reactivation, upregulation and accumulation of p53 in response to ionizing irradiation initiated the caspase lethal pathway, achieving programmed cell death.

\section{TGF- $\beta$ and response to irradiation}

TGF- $\beta$ was considered as the major altered pathway explained in keloids' pathogenesis, especially at early stages. ${ }^{[50]}$ More than $90 \%$ immunostaining in keloids was significantly higher than the $60 \%$ found in normal scars. Significant elevation of TGF- $\beta$ expression was observed in keloid tissue compared to normal tissue, which may be explained by alteration expression of SMAD3, SMAD6 and SMAD7. ${ }^{[51]}$ Specifically, 
downregulation of Dickkopf-3 (DKK3) in keloids fibroblasts disinhibited cell proliferation in TGF- $\beta 1$ induced keloid fibroblasts transfected with pcDNA3 through downregulated Bax and caspase- 3 expression and increase expression of Bcl-2. ${ }^{[52]}$ Additionally, dramatic overproduction of collagen proteins and mRNAs was also contributed to DKK3 overexpression, which made DKK3 a potential mediator functioning in TGF- $\beta / S M A D$ signaling pathway. Overexpression of TGF- $\beta$ can explain overproduction of collagen and extracellular matrix, ${ }^{[53]}$ outweighing other postulated pathways explaining the pathogenesis. ${ }^{[54]}$ Immune system including T-cell function and keloid fibroblasts proliferation were included in this process. ${ }^{[55]}$ Radiation therapy can induce and enhance TGF- $\beta$ signaling in radiation oncology, which means this process was much less important in keloid treatment. ${ }^{[56]}$ Several literatures reported that radiation could potentially induce persistent TGF- $\beta$ overproduction in animal models. ${ }^{[57-59]}$ In radiation induced fibrosis, high doses of radiation can be delivered to the skin and the underlying subcutaneous tissues, and severe skin burns can be observed, resulting in extensive fibronecrotic tissues. ${ }^{[60]}$ TGF- $\beta 1$ was observed sustainably overexpressed in all phases of skin fibrosis, especially in late phase of fibrosis at a level of 10 folds more than underlying tissue. In human patients, similar long-term activation of TGF- $\beta$ expression pattern was found in mammary skin biopsies from breast cancer patients who had received radiation therapy up to 10 years before. Considering the parallel relation between keloid scarring and skin fibrosis, TGF- $\beta$ pathway is less likely to be target of radiation therapy in treating keloid lesions. However, TGF- $\beta$ overexpression could potentially provide plausible explanation of some radiation-refractory patients, explaining their higher rates of recurrence. Therefore, direct and indirect DNA damage and p53induced apoptosis possibly outweigh TGF- $\beta$ signaling activation in keloid radiation therapy treatment.

\section{Other potential responses}

TNF receptor superfamily not only coordinates with p53 in canonical extrinsic apoptotic pathway, but also induces necrosis by TNF (alpha)-PARP-jnkCaspases pathway. ${ }^{[61]}$ The signaling cascade ULK-1 initiated the process of autophagy, upregulating Hif1a and blocking $\mathrm{Bcl}-2$ and, finally releasing Beclin1. ${ }^{[62]}$ Beclin1 was deemed as the initiator of autophagy. Antiinflammation effect was considered playing the minor role in treating keloids and other proliferative benign disease. ${ }^{[63]}$ Moreover, PI3K/Akt/mTOR pathway can potentially enhance the tissue sensitivity towards the radiation damage through inducing apoptosis, reducing autophagy, suppressing NHEJ and HR repair pathways. ${ }^{[64]}$ Inhibition of mTOR pathway could potentially enhance damage towards lesion vasculature and obviously decrease inflammation. ${ }^{[6]}$ However, we believe that mTOR pathway is central to some solid tumor formation, which is not the case in keloid formation. Besides, inflammation is initial phase of wound healing process and also keloid formation process, IL-6 is one of key cytokines mediating inflammation. Overexpression of IL-6 first reported in 1990s, both in keloid fibroblasts culture and collagen synthesis. ${ }^{[66]}$ IL-6 is not only accumulated in collagen, but also related to JAK/STAT3 and ERK/MAP kinase. In an epidemiological study in China, a marked increase in serum IL-6 levels in KS patients with GG genotypes when compared to keloids patients harboring the CC genotype indicating IL-6 polymorphisms is partially related to keloid susceptibility. ${ }^{[67]}$ Recently, a case report demonstrated a Castleman's disease (a rare lymphoproliferative disorder) patient developed bilateral auricular keloids, which is believed due to overproduction of IL-6 in Castleman's disease patients ${ }^{[68]}$ Moreover, antibody towards IL-6 resulted in reduced collagen accumulation which made IL-6 a target for pharmacologic intervention. However, no post-radiation therapy can potentially support this assumption. From genetics to epigenetics is another very important issue in the past few years. The fact that the proportion of apoptotic cells in keloid fibroblasts can be modulated by methylation inhibitors indicated that methylation also plays an important role in keloid formation. ${ }^{[69]}$ DNMT1, DNA methyltransferase 1, a well-known DNA methyltransferase, expressed $100 \%$ in keloid tissue compared to $8 \%$ in normal skin tissue. ${ }^{[70]}$ In one study working on relevance between methylation levels and radiation therapy, clear difference induced by radiation therapy is observed. ${ }^{[71]}$ Moreover, histonedeacetylase 2 (HDAC2) upregulated in keloid tissue in vivo, was also observed in scar tissue mice model of wound repair. ${ }^{[72]}$ Notably, the capacity of the HDAC inhibitor suberoylanilide hydroxamic acid to modulate radiation response in human tumor cell lines is verified in another study, demonstrating a dosedependent inhibition effect. The radiation-induced apoptosis was significantly enhanced. ${ }^{[73]}$ Acetylation level of histone is also altered after radiation therapy in lymphoblastoid cell lines. ${ }^{[7]}$ Therefore, even though valid evidence is absent, we can still predict that the methylation and histone post-translational modification levels will change in response to radiation therapy. Besides, a recent new perspective of keloid and hypertrophic scars renders these two disorders as vascular disease. ${ }^{[75]}$ All so-called effective treatments of keloids including radiotherapy, compression therapy, steroid administration, and long-pulsed Nd:YAG laser therapy all directly or indirectly damage blood vessels or suppress new blood vessel growth. The 
new assumption is that primary scars are always due to congenital endothelial dysfunction, while secondary scars is always caused by aging. Therefore, keloids and hypertrophic scars tend to appear on younger patients, while normal scars are not. These new evidence and assumptions might indicate the damage towards endothelial cells or preceding blood vessels can partly explain the damage induced by radiation therapy.

\section{Long non-coding RNA and microRNA}

Long non-coding RNA (IncRNA) and microRNA are both hot issues in the past decades, especially in oncology. The IncRNAs and microRNAs were both unearthed being involved in pathological process of keloid formation, which is assumed to have potential to partially explain the cellular response to radiation therapy. The microarray technology was first applied in study of keloids in our hospital. ${ }^{[76]}$ Our published data demonstrated that 1,731 IncRNAs constantly upregulated and 782 downregulated, 1,079 mRNAs upregulated and 3,282 downregulated in keloid respectively (fold change $\geq 2.0, P<0.05$ ). Some selected 3 upregulated and 1 downregulated IncRNA were re-confirmed by performing quantitative real time polymerase chain reaction (qRT-PCR). We had 55 pathways highlighted in total, 11 pathways related with upregulated transcripts and 44 with downregulated in keloid. What's more, the CACNA1G-AS1, one of the selected IncRNA potentially functions vitally in keloid formation. In another study working on ear-lobe keloids also by microarray, a total of 2,068 IncRNAs and 1,511 mRNAs differentially expressed between earlobe keloid and normal tissues were identified. ${ }^{[76]}$ Similarly, more than 1,000 IncRNAs and mRNAs were upregulated, with another several hundreds of IncRNAs and mRNAs downregulated. In this study, 35 pathways were also highlighted. However, the IncRNAs regulating encoding transcripts/genes involved in Wnt signaling pathway in keloids is previously reported. ${ }^{[35]}$ Eleven top co-expressed IncRNAs characterized with the highest co-expression coefficients to the 17 identified skin-related keloid-aberrant Wnt-genes. After PCR confirmation, 4 IncRNAs including CACNA1GAS1, HOXA11-AS, LINC00312 and RP11-91I11.1 with their 6 paired Wnt-genes were believed to function in keloid formation. These IncRNAs responded to the pre-designed array and GPCR test simultaneously. However, unluckily, no updating data generated from post-irradiation keloid tissue or even cancer tissue supporting this assumption. But IncRNA is now believed to be excellent biomarker for predicting breast cancer and prostate cancer survival, which will lead us to keep our eyes closed on this area. MicroRNAs are 21-23 nucleotide molecule, which are not participated in protein synthesis but targeting the 3'UTR of mRNA. ${ }^{[7]}$ MicroRNAs were considered playing roles in multiple stages of cancer development, including cell proliferation, apoptosis and migration. Reasonably, microRNA deregulation was believed to indicate clinical intervention. A number of microRNAs have been identified due to differentially expression in keloid tissues and keloid fibroblasts. In the study published in 2012, a total of 32 differentially expressed in keloid tissues comparatively. ${ }^{[78]}$ Among them, 23 miRNAs (e.g. miR-21, miR-4269, miR-382) were upregulated and 9 miRNAs were downregulated (e.g. miR-203, miR-205, miR-200b/c), which participated in some important signaling pathways functioning in wound healing process or scar formation, specifically mitogen-activated protein kinase, focal adhesion and biosynthesis of collagen protein ${ }^{\left[{ }^{79]}\right.}$ Furthermore, these differential-expressed microRNAs were observed as major function in keloid fibroblasts. The altered microRNA profiling narrowed down to 6 upregulated and 3 downregulated microRNA genes. Meanwhile, microRNAs were considered playing important regulatory roles in various pathways, at least in cancer treatment. ${ }^{[80]}$ These microRNAs were functioning in different aspects, including DNA damage response, the microenvironment and survival pathways and other radioresistance-related pathways. Some microRNAs were reported in both the function of keloid formation process and the response to radiation therapy process. For example, miR-21 is believed to promote phosphatidylinositol 3 kinase-AKT-pathway-mediated survivals by suppressing its direct and indirect negative regulators PTEN, deemed as one of vital survival pathways. Therefore, miR21 was regarded as one of the most promising targets for RNA-based therapy in treatment of breast cancer. Triggered by diverse stimuli including ionizing radiation, autophagy is considered as a self-degrading process. ${ }^{\left[{ }^{[1]}\right.}$ MiR-199$5 p$ is also considered as an autophagy suppressor in MCF7 cells. MiR-199-5p also delivers radiosensitive potential to breast cancer cell lines. ${ }^{[82,83]}$ MiR-199a-5p overexpression inhibits DRAM 1 and Beclin 1 expression in MCF7 cells and also sensitizes MDA-MB-231 cells to irradiation. This novel microRNA is now considered as one of the therapeutic target. ${ }^{[84]}$ In another study, miR-199a-5p is believed to have an influence on the proliferation of keloid fibroblasts. Transfection of different overly expressed miRNAs into a keloid fibroblast with EdU assay showed a significant downregulated cell proliferation rate and altered cell cycles. ${ }^{[55]}$ Moreover, miR200b and miR200c, both belonging to miR200 family, were associated to aberrant proliferation of fibroblasts and radiation-induced apoptosis, respectively. ${ }^{[86-88]} \mathrm{MiR}-200 \mathrm{~b}$ was downregulated by more than 2-fold in hypertrophic scars, regulating the 
cell proliferation and apoptosis of human hypertrophic scar fibroblasts through affecting collagen I and III, fibronectin expression and TGF- $\beta 1 / \alpha-S M A$ signaling. ${ }^{[88]}$ On the contrary, miR-200c overexpression could sensitize human breast cancer cells through escalation of apoptosis and DNA double-strand breaks. Another phenomenon is that overexpression of TBK1 can partially rescue apoptosis induced by miR200c. We predict that miR-200b could demonstrate similar effect on keloid tissue radiosensitization. Along by more and more microRNAs identified being related to keloid formation or cellular response to radiation therapy, these microRNAs will be candidates for therapeutic targets in radio-sensitization. ${ }^{\left[{ }^{[9]}\right.}$

\section{Similarity and distinction to cancer cell, and its response to radiation}

Regarded as a benign tumor, keloids demonstrate some similarities of malignant tumors. Aberrant cell growth pattern, indefinite proliferation, increased proliferation rate and familial tendency enabled the application of radiation therapy in disposing this frustrating clinical problem. Compared to cancer cells, benign growth pattern of keloids do not exhibit the strong invasiveness and strong capacity of distant metastasis. And molecular mechanisms varied largely between keloid and malignant tumors. Specifically narrowing down to keloid fibroblast response to ionizing irradiation, multiple genetic interrelated pathways were identified from different resources, like wholegenome sequence or some inherited familial pattern discovered. ${ }^{[90]}$ Apoptotic and senescent cells were identified from X-ray irradiation keloid tissues based on extended G0/G1 phase and overexpression of p16, p21 and p27, which were all senescence-related genes. ${ }^{[91]} \mathrm{IL}-6$, as one of interleukins functioning in induced inflammations, was firstly identified based on bioinformatics analysis of post-irradiation keloid fibroblasts global gene expression, ${ }^{[92]}$ which seldom reports in other malignant tumors response towards irradiation. Further evidence supporting this hypothesis ensued. IL-6 was then reported playing a critical role in benign tumor-like stem cell similar to keloid derived precursor cells, suggesting inducing stem cell associated gene overexpression, then indirectly uncontrolled self-renewal and increased proliferation. ${ }^{[93]}$ The updating concept of keloid progenitor cells, exhibit clonogenicity, self-renewal, distinct embryonic and mesenchymal stem cell surface markers, and multipotent differentiation, indicating similar resistance derived from cancer stem cells. ${ }^{[94]}$ Furthermore, in contrast to cancer cells, keloid cells displayed enhanced apoptosis ratio in response to hypoxia, which was thought as the key initiator enabling radioresistance through HIF-1 and VEGF dysregulation, ${ }^{[95]}$ while cancer cells radiation therapy resistance is largely thought dependent on hypoxia. ${ }^{[96-98]}$

\section{CONCLUSION}

We are still far away from generating a comprehensive understanding of the underlying mechanisms in radiation therapy for keloid. Lack of detailed fundamental studies also prevented us from uncovering the precise differences between radiation therapy treating keloids or cancer cells. However, relatively lower genome instability and lower growth rate possibly indicate that the direct effect might outweigh the indirect effect in killing keloid fibroblasts. Cellular response to irradiation also varies between keloids fibroblasts and cancer cells, ascribing to comparatively intact DNA repair system. Some genes which were thought to have the potential to drive keloid formation and differentially expressed prior or post irradiation should be regarded as therapeutic targets. Furthermore, updating study of pathogenesis of keloids including microRNA dysregulation and epigenetics might provide us with more potential in exploring the keloids cells' targets of radiation therapy. ${ }^{[99]}$ Currently, there are biological and antineoplastic agents that can potentially treat and prevent excessive scar formation. ${ }^{[100]}$ However, prevention is the best way to avoid the development of cosmetically unacceptable scars. Clinically, although numerous treatments exist, no single modality has been proven superior over others. ${ }^{[101]}$ Evidence in pediatric patients indicates that Asian patients have a three-fold increased rate of hypertrophic scarring relative to Caucasians. ${ }^{[102]}$ According to the guideline update on scar management for treating Asian patients, it is recommended that all Asian patients should initiate scar prevention following surgery. ${ }^{[103]}$ Figuring out the molecular mechanism of keloid could eventually help the clinicians to better treat their patients, especially among the Asian population. Understanding the molecular pathway in how to decrease profibrotic isoform could be crucial in accomplishing control of the fibrotic process underlying keloids. Comprehension of the molecular mechanisms could lead to the development of new promising therapies for keloids.

\section{Authors' contributions}

Conception and design of the study: X. Long

Literature search and analysis : J. Xu

Drafting the article: J. Xu, E. Yang, N.Z. Yu, Y.B. Wang

\section{Financial support and sponsorship}

None.

\section{Conflicts of interest}

There are no conflicts of interest. 


\section{Patient consent}

Not applicable.

\section{Ethics approval}

Not applicable.

\section{REFERENCES}

1. Bennett KG, Kung TA, Hayman JA, Brown DL. Treatment of keloids with excision and adjuvant radiation: a single center experience and review of the literature. Ann Plast Surg 2017;78:157-61.

2. Ogawa R, Hsu CK. Mechanobiological dysregulation of the epidermis and dermis in skin disorders and in degeneration. $J$ Cell Mol Med 2013;17:817-22.

3. Ha JM, Kim HS, Cho EB, Park GH, Park EJ, Kim KH, Kim LS, Kim KJ. Comparison of the effectiveness of nonablative fractional laser versus pulsed-dye laser in thyroidectomy scar prevention. Ann Dermatol 2014;26:615-20.

4. Rabello FB, Souza CD, Farina Junior JA. Update on hypertrophic scar treatment. Clinics (Sao Paulo) 2014;69:565-73.

5. Supp DM, Hahn JM, McFarland KL, Glaser K. Inhibition of hyaluronan synthase 2 reduces the abnormal migration rate of keloid keratinocytes. J Burn Care Res 2014;35:84-92.

6. Ogawa R. Keloid and hypertrophic scars are the result of chronic inflammation in the reticular dermis. Int J Mol Sci 2017;18:E606.

7. Andrews JP, Marttala J, Macarak E, Rosenbloom J, Uitto J. Keloids: the paradigm of skin fibrosis - pathomechanisms and treatment. Matrix Biol 2016;51:37-46.

8. van den Broek LJ, Limandjaja GC, Niessen FB, Gibbs S. Human hypertrophic and keloid scar models: principles, limitations and future challenges from a tissue engineering perspective. Exp Dermatol 2014:23:382-6.

9. Zonari A, Martins TM, Paula AC, Boeloni JN, Novikoff S, Marques AP, Correlo VM, Reis RL, Goes AM. Polyhydroxybutyrate-cohydroxyvalerate structures loaded with adipose stem cells promote skin healing with reduced scarring. Acta Biomater 2015;17:170-81.

10. Hahn JM, Glaser K, McFarland KL, Aronow BJ, Boyce ST, Supp DM. Keloid-derived keratinocytes exhibit an abnormal gene expression profile consistent with a distinct causal role in keloid pathology. Wound Repair Regen 2013;21:530-44

11. Ma X, Chen J, Xu B, Long X, Qin H, Zhao RC, Wang X. Keloidderived keratinocytes acquire a fibroblast-like appearance and an enhanced invasive capacity in a hypoxic microenvironment in vitro. Int J Mol Med 2015;35:1246-56.

12. Douaiher J, Succar J, Lancerotto L, Gurish MF, Orgill DP, Hamilton MJ, Krilis SA, Stevens RL. Development of mast cells and importance of their tryptase and chymase serine proteases in inflammation and wound healing. Adv Immunol 2014;122:211-52.

13. Har-Shai Y, Sommer A, Gil T, Krausz J, Gal-Or N, Mettanes I, Lavi I, Eyal N, Brizgalin L, Taran A, Har-Shai L, Elmalach I. Intralesional cryosurgery for the treatment of basal cell carcinoma of the lower extremities in elderly subjects: a feasibility study. Int $J$ Dermatol 2016;55:342-50

14. Pakyari M, Farrokhi A, Maharlooei MK, Ghahary A. Critical role of transforming growth factor beta in different phases of wound healing. Adv Wound Care (New Rochelle) 2013;2:215-24.

15. Wang YW, Liou NH, Cherng JH, Chang SJ, Ma KH, Fu E, Liu JC, Dai NT. siRNA-targeting transforming growth factor-beta type I receptor reduces wound scarring and extracellular matrix deposition of scar tissue. J Invest Dermatol 2014;134:2016-25.

16. Shi JH, Guan H, Shi S, Cai WX, Bai XZ, Hu XL, Fang XB, Liu JQ, Tao K, Zhu XX, Tang CW, Hu DH. Protection against TGF- beta 1-induced fibrosis effects of IL-10 on dermal fibroblasts and its potential therapeutics for the reduction of skin scarring. Arch Dermatol Res 2013;305:341-52

17. Walmsley GG, Maan ZN, Wong VW, Duscher D, Hu MS, Zielins ER Wearda T, Muhonen E, McArdle A, Tevlin R, Atashroo DA, SenarathYapa K, Lorenz HP, Gurtner GC, Longaker MT. Scarless wound healing: chasing the holy grail. Plast Reconstr Surg 2015;135:907-17.

18. Ud-Din S, Bowring A, Derbyshire B, Morris J, Bayat A. Identification of steroid sensitive responders versus non-responders in the treatment of keloid disease. Arch Dermatol Res 2013;305:423-32.

19. Jumper N, Hodgkinson T, Arscott G, Har-Shai Y, Paus R, Bayat A. The Aldo-Keto Reductase AKR1B10 is up-regulated in keloid epidermis, implicating retinoic acid pathway dysregulation in the pathogenesis of keloid disease. J Invest Dermatol 2016;136:1500-12.

20. Li ZJ, Kim SM. The application of the starfish hatching enzyme for the improvement of scar and keloid based on the fibroblast-populated collagen lattice. Appl Biochem Biotechnol 2014;173:989-1002.

21. Lee WJ, Choi IK, Lee JH, Kim YO, Yun CO. A novel threedimensional model system for keloid study: organotypic multicellular scar model. Wound Repair Regen 2013;21:155-65.

22. Arno AI, Gauglitz GG, Barret JP, Jeschke MG. Up-to-date approach to manage keloids and hypertrophic scars: a useful guide. Burns 2014;40:1255-66

23. Shaarawy E, Hegazy RA, Abdel Hay RM. Intralesional botulinum toxin type A equally effective and better tolerated than intralesional steroid in the treatment of keloids: a randomized controlled trial. $J$ Cosmet Dermatol 2015;14:161-6.

24. Brewin MP, Lister TS. Prevention or treatment of hypertrophic burn scarring: a review of when and how to treat with the pulsed dye laser. Burns 2014;40:797-804

25. Zhu Z, Ding J, Tredget EE. The molecular basis of hypertrophic scars. Burns Trauma 2016;4:2

26. Seo BF, Lee JY, Jung SN. Models of abnormal scarring. Biomed Res Int 2013;2013:423147.

27. Hwang SH, Hwang K. Outcomes of surgical excision with pressure therapy using magnets and identification of risk factors for recurrent keloids. Plast Reconstr Surg 2013;132:e666-7.

28. Enwerem-Bromson N, Abdel-Wahab M. Expanding global access to radiotherapy: the IAEA perspective. Lancet Oncol 2015;16:1151-2.

29. Arno AI, Gauglitz GG, Barret JP, Jeschke MG. Up-to-date approach to manage keloids and hypertrophic scars: a useful guide. Burns 2014;40:1255-66

30. Shen J, Lian X, Sun Y, Wang X, Hu K, Hou X, Sun S, Yan J, Yu L, Sun X, Li W, Wang X, Guan Q, Pang T, Zhang F. Hypofractionated electron-beam radiation therapy for keloids: retrospective study of 568 cases with 834 lesions. $J$ Radiat Res 2015;56:811-7.

31. Basan M, Elgeti J, Hannezo E, Rappel WJ, Levine H. Alignment of cellular motility forces with tissue flow as a mechanism for efficient wound healing. Proc Natl Acad Sci U S A 2013;110:2452-9.

32. Shah VV, Aldahan AS, Mlacker S, Alsaidan M, Samarkandy S, Nouri K. 5-fluorouracil in the treatment of keloids and hypertrophic scars: a comprehensive review of the literature. Dermatol Ther (Heidelb) 2016;6:169-83.

33. Yamamori T, Ike S, Bo T, Sasagawa T, Sakai Y, Suzuki M, Yamamoto K, Nagane M, Yasui H, Inanami O. Inhibition of the mitochondrial fission protein dynamin-related protein 1 (Drp1) impairs mitochondrial fission and mitotic catastrophe after x-irradiation. Mol Biol Cell 2015;26:4607-17

34. Maier P, Hartmann L, Wenz F, Herskind C. Cellular pathways in response to ionizing radiation and their targetability for tumor radiosensitization. Int J Mol Sci 2016;17:E102.

35. Sun XJ, Wang Q, Guo B, Liu XY, Wang B. Identification of skinrelated IncRNAs as potential biomarkers that involved in Wnt 
pathways in keloids. Oncotarget 2017;8:34236-44.

36. Stamatakos G, Dionysiou D, Lunzer A, Belleman R, Kolokotroni E, Georgiadi E, Erdt M, Pukacki J, Rüeping S, Giatili S, d'Onofrio A, Sfakianakis S, Marias K, Desmedt C, Tsiknakis M, Graf N. The technologically integrated oncosimulator: combining multiscale cancer modeling with information technology in the in silico oncology context. IEEE J Biomed Health Inform 2014;18:840-54.

37. Wick W, Chinot OL, Bendszus M, Mason W, Henriksson R, Saran F, Nishikawa R, Revil C, Kerloeguen Y, Cloughesy T. Evaluation of pseudoprogression rates and tumor progression patterns in a phase III trial of bevacizumab plus radiotherapy/temozolomide for newly diagnosed glioblastoma. Neuro Oncol 2016;18:1434-41.

38. Chinot OL, Wick W, Mason W, Henriksson R, Saran F, Nishikawa R, Carpentier AF, Hoang-Xuan K, Kavan P, Cernea D, Brandes AA, Hilton M, Abrey L, Cloughesy T. Bevacizumab plus radiotherapytemozolomide for newly diagnosed glioblastoma. $N$ Engl J Med 2014;370:709-22.

39. Gadgeel SM, Gandhi L, Riely GJ, Chiappori AA, West HL, Azada MC, Morcos PN, Lee RM, Garcia L, Yu L, Boisserie F, Di Laurenzio L, Golding S, Sato J, Yokoyama S, Tanaka T, Ou SH. Safety and activity of alectinib against systemic disease and brain metastases in patients with crizotinib-resistant ALK-rearranged non-small-cell lung cancer (AF-002JG): results from the dose-finding portion of a phase 1/2 study. Lancet Oncol 2014;15:1119-28.

40. Armstrong TS, Ying Y, Wu J, Acquaye AA, Vera-Bolanos E, Gilbert MR, Brown PD, Vardy J, Chung C. The relationship between corticosteroids and symptoms in patients with primary brain tumors: utility of the Dexamethasone Symptom Questionnaire-Chronic. Neuro Oncol 2015; 17:1114-20

41. Grossman R, Shimony N, Hadelsberg U, Soffer D, Sitt R, Strauss $\mathrm{N}$, Corn BW, Ram Z. Impact of resecting radiation necrosis and pseudoprogression on survival of patients with glioblastoma. World Neurosurg 2016;89:37-41.

42. Das A, McDonald DG, Dixon-Mah YN, Jacqmin DJ, Samant VN, Vandergrift WA 3rd, Lindhorst SM, Cachia D, Varma AK, Vanek KN, Banik NL, Jenrette JM 3rd, Raizer JJ, Giglio P, Patel SJ. RIP1 and RIP3 complex regulates radiation-induced programmed necrosis in glioblastoma. Tumour Biol 2016;37:7525-34.

43. Ladin DA, Hou Z, Patel D, McPhail M, Olson JC, Saed GM, Fivenson DP. p53 and apoptosis alterations in keloids and keloid fibroblasts. Wound Repair Regen 1998;6:28-37.

44. Son D, Harijan A. Overview of surgical scar prevention and management. J Korean Med Sci 2014;29:751-7.

45. Unahabhokha T, Sucontphunt A, Nimmannit U, Chanvorachote P, Yongsanguanchai N, Pongrakhananon V. Molecular signalings in keloid disease and current therapeutic approaches from natural based compounds. Pharm Biol 2015;53:457-63.

46. Filgueiras Mde C, Morrot A, Soares PM, Costa ML, Mermelstein C. Effects of 5-fluorouracil in nuclear and cellular morphology, proliferation, cell cycle, apoptosis, cytoskeletal and caveolar distribution in primary cultures of smooth muscle cells. PLoS One 2013;8:e63177.

47. Huang C, Ogawa R. Pharmacological treatment for keloids. Expert Opin Pharmacother 2013;14:2087-100.

48. De Felice B, Ciarmiello LF, Mondola P, Damiano S, Seru R, Argenziano C, Nacca M, Santoriello M, Garbi C. Differential p63 and 53 expression in human keloid fibroblasts and hypertrophic scar fibroblasts. DNA Cell Biol 2007;26:541-7.

49. Trace AP, Enos CW, Mantel A, Harvey VM. Keloids and hypertrophic scars: a spectrum of clinical challenges. Am J Clin Dermatol 2016;17:201-23.

50. Huang D, Liu YP, Huang Y, Xie Y, Shen K, Zhang D, Mou Y, Mechanical compression upregulates MMP9 through SMAD3 but not
SMAD2 modulation in hypertrophic scar fibroblasts. Connect Tissue Res 2014;55:391-6.

51. Zhang X, Ma Y, You T, Tian X, Zhang H, Zhu Q, Zhang W. Roles of TGF-beta/Smad signaling pathway in pathogenesis and development of gluteal muscle contracture. Connect Tissue Res 2015;56:9-17.

52. Li Y, Liu H, Liang Y, Peng P, Ma X, Zhang X. DKK3 regulates cell proliferation, apoptosis and collagen synthesis in keloid fibroblasts via TGF-beta1/Smad signaling pathway. Biomed Pharmacother 2017;91:174-80

53. Lilja-Maula L, Syrjä P, Laurila HP, Sutinen E, Rönty M, Koli K Rajamäki MM, Myllärniemi M. Comparative study of transforming growth factor-beta signalling and regulatory molecules in human and canine idiopathic pulmonary fibrosis. J Comp Pathol 2014;150:399407.

54. Lu J, Shi J, Li M, Gui B, Fu R, Yao G, Duan Z, Lv Z, Yang Y, Chen Z, Jia L, Tian L. Activation of AMPK by metformin inhibits TGFbeta-induced collagen production in mouse renal fibroblasts. Life Sci 2015;127:59-65.

55. Jette ME, Hayer SD, Thibeault SL. Characterization of human vocal fold fibroblasts derived from chronic scar. Laryngoscope 2013;123:738-45

56. Moding EJ, Kastan MB, Kirsch DG. Strategies for optimizing the response of cancer and normal tissues to radiation. Nat Rev Drug Discov 2013;12:526-42.

57. Wang M, Saha J, Hada M, Anderson JA, Pluth JM, O'Neill P, Cucinotta FA. Novel Smad proteins localize to IR-induced doublestrand breaks: interplay between TGFbeta and ATM pathways. Nucleic Acids Res 2013;41:933-42.

58. Weigel C, Schmezer P, Plass C, Popanda O. Epigenetics in radiationinduced fibrosis. Oncogene 2015;34:2145-55.

59. Russell NS, Floot B, van Werkhoven E, Schriemer M, de JongKorlaar R, Woerdeman LA, Stewart FA, Scharpfenecker M. Blood and lymphatic microvessel damage in irradiated human skin: the role of TGF-beta, endoglin and macrophages. Radiother Oncol 2015;116:455-61.

60. Al-Omair A, Smith R, Kiehl TR, Lao L, Yu E, Massicotte EM, Keith J, Fehlings MG, Sahgal A. Radiation-induced vertebral compression fracture following spine stereotactic radiosurgery: clinicopathological correlation. J Neurosurg Spine 2013;18:430-5.

61. Thibault I, Al-Omair A, Masucci GL, Masson-Côté L, Lochray F, Korol R, Cheng L, Xu W, Yee A, Fehlings MG, Bjarnason GA, Sahgal A. Spine stereotactic body radiotherapy for renal cell cancer spinal metastases: analysis of outcomes and risk of vertebral compression fracture. J Neurosurg Spine 2014;21:711-8.

62. Honscheid P, Datta K, Muders MH. Autophagy: detection, regulation and its role in cancer and therapy response. Int $J$ Radiat Biol 2014;90:628-35

63. Canyilmaz E, Canyilmaz F, Aynaci O, Colak F, Serdar L, Uslu GH, Aynaci O, Yoney A. Prospective randomized comparison of the effectiveness of radiation therapy and local steroid injection for the treatment of plantar fasciitis. Int J Radiat Oncol Biol Phys 2015;92:659-66.

64. Chang L, Graham PH, Hao J, Ni J, Bucci J, Cozzi PJ, Kearsley JH, Li Y. PI3K/Akt/mTOR pathway inhibitors enhance radiosensitivity in radioresistant prostate cancer cells through inducing apoptosis, reducing autophagy, suppressing NHEJ and HR repair pathways. Cell Death Dis 2014;5:e1437.

65. Chinnaiyan $\mathrm{P}$, Won $\mathrm{M}$, Wen PY, Rojiani AM, Wendland M, Dipetrillo TA, Corn BW, Mehta MP. RTOG 0913: a phase 1 study of daily everolimus (RAD001) in combination with radiation therapy and temozolomide in patients with newly diagnosed glioblastoma. Int J Radiat Oncol Biol Phys 2013;86:880-4.

66. Van Linthout S, Miteva K, Tschöpe C. Crosstalk between fibroblasts 
and inflammatory cells. Cardiovasc Res 2014;102:258-69.

67. Zhu XJ, Li WZ, Li H, Fu CQ, Liu J. Association of interleukin-6 gene polymorphisms and circulating levels with keloid scars in a Chinese Han population. Genet Mol Res 2017;16:16029110.

68. Quong WL, Kozai Y, Ogawa R. A case of keloids complicated by Castleman's disease: interleukin-6 as a keloid risk factor. Plast Reconstr Surg Glob Open 2017;5:e1336.

69. Zou QP, Yang E, Zhang HS. Effect of the methylation enzyme inhibitors of 5-aza-2-deoxycytidine on the TGF-beta/smad signal transduction pathway in human keloid fibroblasts. Zhonghua Zheng Xing Wai Ke Za Zhi 2013;29:285-9. (in Chinese)

70. Yang E, Zou Q, Zhang H. The expression of DNMT1 in pathologic scar fibroblasts and the effect of 5-aza-2-deoxycytidine on cytokines of pathologic scar fibroblasts. Wounds 2014;26:139-46.

71. Halvorsen AR, Helland A, Fleischer T, Haug KM, Grenaker Alnaes GI, Nebdal D, Syljuåsen RG, Touleimat N, Busato F, Tost J, Saetersdal AB, Børresen-Dale AL, Kristensen V, Edvardsen H. Differential DNA methylation analysis of breast cancer reveals the impact of immune signaling in radiation therapy. Int J Cancer 2014;135:2085-95.

72. Spallotta F, Cencioni C, Straino S, Nanni S, Rosati J, Artuso S, Manni I, Colussi C, Piaggio G, Martelli F, Valente S, Mai A, Capogrossi MC, Farsetti A, Gaetano C. A nitric oxide-dependent cross-talk between class $\mathrm{i}$ and iii histone deacetylases accelerates skin repair. J Biol Chem 2013;288:11004-12

73. Chinnaiyan P, Vallabhaneni G, Armstrong E, Huang SM, Harari PM. Modulation of radiation response by histone deacetylase inhibition. Int J Radiat Oncol Biol Phys 2005;62:223-9.

74. Maroschik B, Gürtler A, Krämer A, Rößler U, Gomolka M, Hornhardt S, Mörtl S, Friedl AA. Radiation-induced alterations of histone posttranslational modification levels in lymphoblastoid cell lines. Radiat Oncol 2014;9:15.

75. Ogawa R, Akaishi S. Endothelial dysfunction may play a key role in keloid and hypertrophic scar pathogenesis - keloids and hypertrophic scars may be vascular disorders. Med Hypotheses 2016;96:51-60.

76. Liang X, Ma L, Long X, Wang X. LncRNA expression profiles and validation in keloid and normal skin tissue. Int J Oncol 2015;47:182938

77. Kaboli PJ, Rahmat A, Ismail P, Ling KH. MicroRNA-based therapy and breast cancer: a comprehensive review of novel therapeutic strategies from diagnosis to treatment. Pharmacol Res 2015;97:10421.

78. Liu Y, Yang DP, Xiao ZB, Zhang MB. miRNA expression profiles in keloid tissue and corresponding normal skin tissue. Aesthet Plast Surg 2012:36:193-201.

79. Rustad KC, Wong VW, Gurtner GC. The role of focal adhesion complexes in fibroblast mechanotransduction during scar formation. Differentiation 2013;86:87-91.

80. Korpela E, Vesprini D, Liu SK. MicroRNA in radiotherapy: miRage or miRador? Br J Cancer 2015;112:777-82.

81. Zhu H, Huang L, Zhu S, Li X, Li Z, Yu C, Yu X. Regulation of autophagy by systemic admission of microRNA-141 to target HMGB1 in L-arginine-induced acute pancreatitis in vivo. Pancreatology 2016;16:337-46.

82. Shin VY, Siu JM, Cheuk I, Ng EK, Kwong A. Circulating cell-free miRNAs as biomarker for triple-negative breast cancer. $\mathrm{Br} J$ Cancer 2015;112:1751-9.

83. Zhang PX, Cheng J, Zou S, D’Souza AD, Koff JL, Lu J, Lee PJ, Krause DS, Egan ME, Bruscia EM. Pharmacological modulation of the AKT/microRNA-199a-5p/CAV1 pathway ameliorates cystic fibrosis lung hyper-inflammation. Nat Commun 2015;6:6221.

84. Yi H, Liang B, Jia J, Liang N, Xu H, Ju G, Ma S, Liu X. Differential roles of miR-199a-5p in radiation-induced autophagy in breast cancer cells. FEBS Lett 2013;587:436-43.

85. Wu ZY, Lu L, Liang J, Guo XR, Zhang PH, Luo SJ. Keloid microRNA expression analysis and the influence of miR-199a-5p on the proliferation of keloid fibroblasts. Genet Mol Res 2014;13:2727-38.

86. Lin J, Liu C, Gao F, Mitchel RE, Zhao L, Yang Y, Lei J, Cai J. miR200c enhances radiosensitivity of human breast cancer cells. $J$ Cell Biochem 2013;114:606-15.

87. Kurashige J, Mima K, Sawada G, Takahashi Y, Eguchi H, Sugimach K, Mori M, Yanagihara K, Yashiro M, Hirakawa K, Baba H, Mimori $\mathrm{K}$. Epigenetic modulation and repression of miR-200b by cancerassociated fibroblasts contribute to cancer invasion and peritoneal dissemination in gastric cancer. Carcinogenesis 2015;36:133-41.

88. Li P, He QY, Luo CQ. Overexpression of miR-200b inhibits the cell proliferation and promotes apoptosis of human hypertrophic scar fibroblasts in vitro. J Dermatol 2014;41:903-11.

89. Feng J, Xue S, Pang Q, Rang Z, Cui F. miR-141-3p inhibits fibroblast proliferation and migration by targeting GAB1 in keloids. Biochem Biophys Res Commun 2017;490:302-8.

90. Chang L, Graham PH, Hao J, Bucci J, Cozzi PJ, Kearsley JH, Li Y Emerging roles of radioresistance in prostate cancer metastasis and radiation therapy. Cancer Metastasis Rev 2014;33:469-96.

91. Ji J, Tian Y, Zhu YQ, Zhang LY, Ji SJ, Huan J, Zhou XZ, Cao JP. Ionizing irradiation inhibits keloid fibroblast cell proliferation and induces premature cellular senescence. J Dermatol 2015;42:56-63.

92. Igota S, Tosa M, Murakami M, Egawa S, Shimizu H, Hyakusoku H, Ghazizadeh M. Identification and characterization of Wnt signaling pathway in keloid pathogenesis. Int J Med Sci 2013;10:344-54.

93. Zhang Q, Yamaza T, Kelly AP, Shi S, Wang S, Brown J, Wang L, French SW, Shi S, Le AD. Tumor-like stem cells derived from human keloid are governed by the inflammatory niche driven by IL-17/IL-6 axis. PLoS One 2009;4:e7798.

94. Meacham CE, Morrison SJ. Tumour heterogeneity and cancer cell plasticity. Nature 2013;501:328-37.

95. Gao J, Chen Y, Liao N, Zhao W, Zeng W, Li Y, Wang S, Lu F. Relationship between p53 gene codon-72 polymorphisms and hypertrophic scar formation following caesarean section. Exp Ther Med 2014;7:1243-6.

96. Nakano T, Suzuki Y, Ohno T, Kato S, Suzuki M, Morita S, Sato $\mathrm{S}$, Oka K, Tsujii H. Carbon beam therapy overcomes the radiation resistance of uterine cervical cancer originating from hypoxia. Clin Cancer Res 2006;12:2185-90.

97. Abbasi AZ, Gordijo CR, Amini MA, Maeda A, Rauth AM, DaCosta $\mathrm{RS}, \mathrm{Wu} \mathrm{XY}$. Hybrid manganese dioxide nanoparticles potentiate radiation therapy by modulating tumor hypoxia. Cancer Res 2016;76:6643-56

98. Huang WJ, Chen WW, Zhang X. Glioblastoma multiforme: effect of hypoxia and hypoxia inducible factors on therapeutic approaches. Oncol Lett 2016;12:2283-8.

99. He Y, Deng Z, Alghamdi M, Lu L, Fear MW, He L. From genetics to epigenetics: new insights into keloid scarring. Cell Prolif 2017;50:12326

100. Polat M, Kaya H, Sahin A. A new approach in the treatment of keloids: UVA-1 laser. Photomed Laser Surg 2016;34:130-3.

101. Commander SJ, Chamata E, Cox J, Dickey RM, Lee EI. Update on postsurgical scar management. Semin Plast Surg 2016;30:122-8.

102. Soltani AM, Francis CS, Motamed A, Karatsonyi AL, Hammoudeh JA, Sanchez-Lara PA, Reinisch JF, Urata MM. Hypertrophic scarring in cleft lip repair: a comparison of incidence among ethnic groups. Clin Epidemiol 2012;4:187-91.

103. Kim S, Choi TH, Liu W, Ogawa R, Suh JS, Mustoe TA. Update on scar management: guidelines for treating Asian patients. Plast Reconstr Surg 2013;132:1580-9. 